\title{
In situ reconstruction of an MRSA-infected paravisceral aortic pseudoaneurysm with cryopreserved aortic allograft
}

\author{
PETER BANGA, PETER LEGEZA*, ZOLTÁN SZEBERIN \\ Department of Vascular Surgery, Semmelweis University, Budapest, Hungary \\ *Corresponding author: Peter Legeza, MD; Department of Vascular Surgery, Semmelweis University, Varosmajor u. 68, 1122 Budapest, Hungary; \\ Phone: +36 20825 9736; Fax: +36 l 458 6842; E-mail: peterlegeza@gmail.com
}

(Received: August 3, 2018; Revised manuscript received: April 12, 2019; Accepted: April 12, 2019)

\begin{abstract}
Objectives: Treatment of paravisceral aortic infections poses several challenges because standard therapy with excision of all infected tissues and extraanatomic reconstruction is frequently not possible without jeopardizing visceral perfusion. In situ reconstruction with rifampin-soaked prosthetic graft or endovascular repair with stent grafts runs the risk of reinfection. We present a case of a paravisceral aortic infection, where cryopreserved allograft was used for the reconstruction of the aorta. Methods: Medical documentation and CT angiography studies were retrospectively reviewed for a patient in a tertiary care center. Results: A 62-year-old male patient presented with an infected pseudoaneurysm of the paravisceral aorta at the level of the celiac artery. He had previously undergone multiple orthopedic surgical interventions and developed methicillin-resistant Staphylococcus aureusinfections. We successfully repaired the paravisceral pseudoaneurysm with excision of all infected tissues and in situ aortic replacement with a cryopreserved allograft. Conclusion: In case of infected aortic pseudoaneurysm, the use of cryopreserved aortic allograft is a reliable choice for reconstruction of the aorta.
\end{abstract}

Keywords: aortic pseudoaneurysm, cryopreserved allograft, MRSA, infection, suprarenal aortic surgery, sepsis

\section{Introduction}

Primary infected aortic pseudoaneurysms (mycotic aneurysms) are found to be rare but they have been described in all segments of the aorta. The paravisceral aortic segment has been reported as the least frequent site of infections. The risk of rupture and death depends on the location, the extent of infection, and the type of bacterial infection of the pseudoaneurysm. Anastomotic disruption and bleeding are the most lethal complication of in situ reconstructions. Therefore, prosthetic reconstruction is not recommended in the presence of periaortic abscess or grossly purulent infection [1]. Successful in situ reconstructions have been reported in infected fields in the infrarenal location [2]. We report a successful in situ aortic repair with cryopreserved allograft in a case of an infected paravisceral aortic pseudoaneurysm.

\section{Case Report}

A 62-year-old male patient presented with the history of diabetes mellitus and hypertension along with abdominal pain and a palpable pulsatile epigastric mass. The patient had undergone bilateral total hip replacements, which subsequently got infected. He was initially treated with levofloxacin, teicoplanin, and vancomycin. The implants were removed and joint spacers were implanted. Blood and tissue cultures demonstrated methicillin-resistant Staphylococcus aureus (MRSA) and proteus mirabilis. Although all prosthetic materials were removed, the patient continued to develop fever for several weeks. Computed tomography (CT) demonstrated a septic spleen without other pathologies. A splenectomy was performed.

Two months later, the patient showed clinical signs of recurrent sepsis with a white blood count of $12,000 / \mathrm{mm}^{3}$.

This is an open-access article distributed under the terms of the Creative Commons Attribution-NonCommercial 4.0 International License, which permits unrestricted use, distribution, and reproduction in any medium for non-commercial purposes, provided the original author and source are credited, a link to the CC License is provided, and changes - if any - are indicated. 


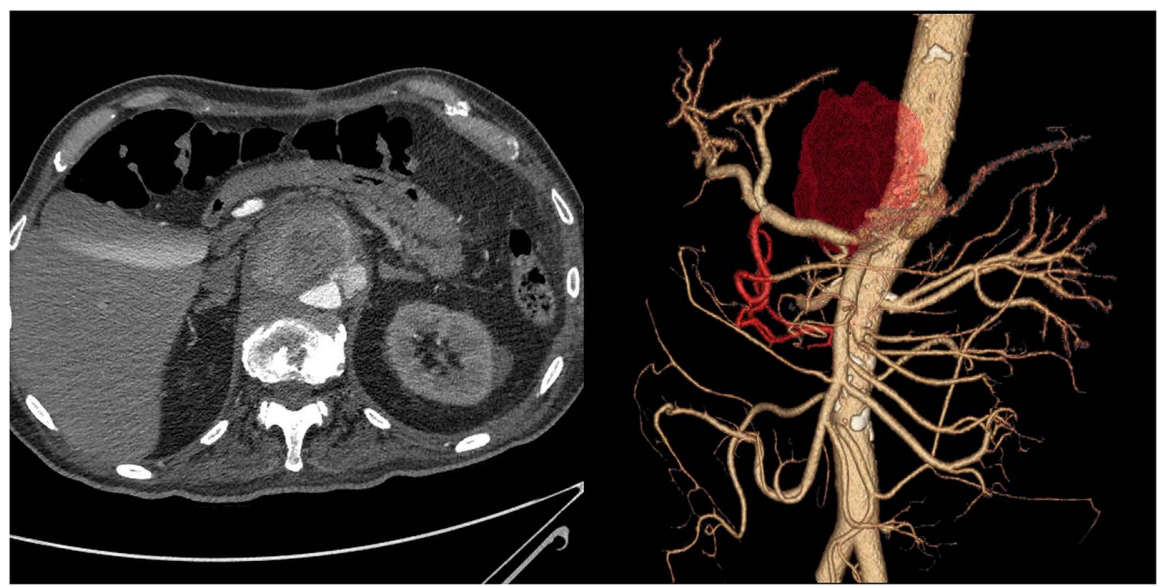

Fig. 1. Axial image and 3D reconstruction of the patient's diagnostic CT angiogram demonstrating a paravisceral aortic pseudoaneurysm at the origin of the celiac artery

CT angiography (CTA) revealed a $60-\mathrm{mm}$ paravisceral aortic pseudoaneurysm at the origin of the celiac artery (CA) (Fig. 1).

The patient was transferred to our tertiary care vascular surgical center. Written consent was obtained from the patient. Placement of a covered stent into the CA was attempted to prevent aneurysm rupture but this was technically unsuccessful.

Through a midline laparotomy, the paravisceral aorta was exposed through the lesser sac and the infrarenal aorta was exposed distal to the pancreas (Fig. $2 \mathrm{~A}$ and $2 \mathrm{~B}$ ). The crura of the diaphragm were divided to facilitate aortic clamping. The aorta was clamped proximal to the $\mathrm{CA}$ and below the renal arteries. Then, the pseudoaneurysm was opened and all infected tissues and necrotic aortic wall were removed. The reconstruction of the CA was not feasible due to the necrotic tissues and the infected environment. The patient had a well-developed gastroduodenal arcade to the common hepatic artery from the superior mesenteric artery (SMA) and the splenic artery was ligated earlier during splenectomy; therefore, we ligated the distal CA. The pseudoaneurysm was excised to healthy-appearing aortic tissue. The aorta proximal to the SMA was repaired with a $4 \times 2 \mathrm{~cm}$ cryopreserved human aortic allograft patch, after thorough debridement (Fig. 2C). The aortic cross clamp time was $34 \mathrm{~min}$.

Postoperatively, the patient stayed in the intensive care unit for 2 days. Blood cultures repeatedly confirmed MRSA infection, but tissue culture from the aortic wall was free from bacteria. He was dismissed from the hospital to a rehabilitation facility with meropenem on postoperative day 7. At 1-year follow-up, the patient remained free of infection without antibiotics; control CTA showed patent SMA and renal arteries without pseudoaneurysm or any symptom of infection.
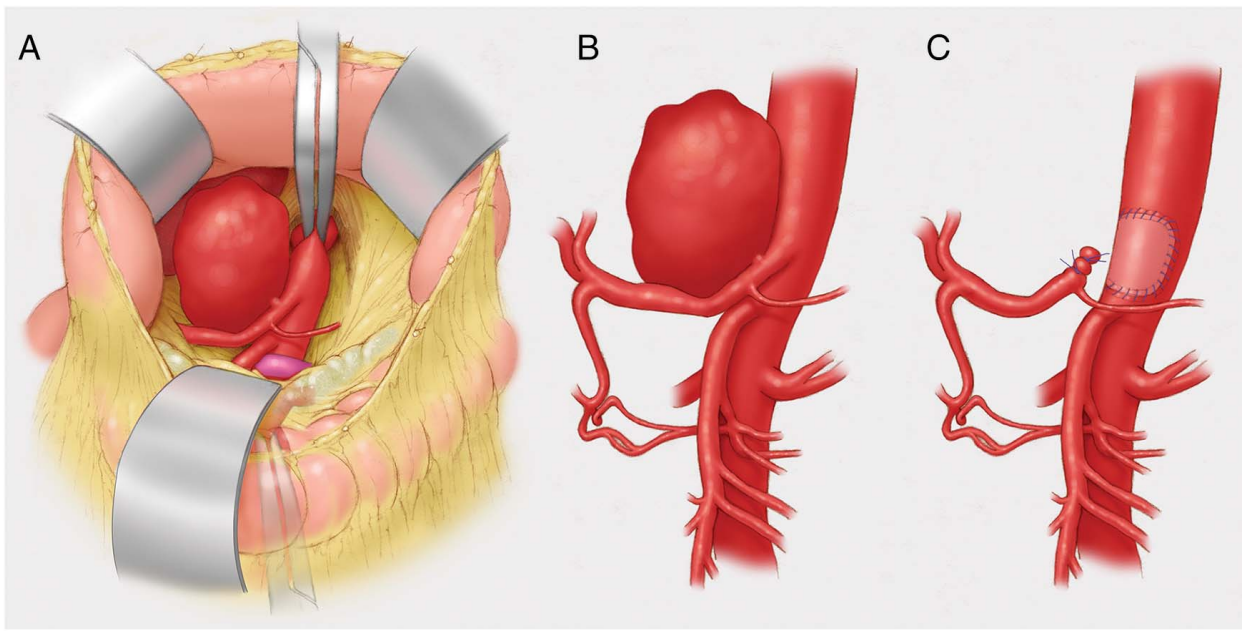

Fig. 2. Images showing the exposed and clamped aorta with the pseudoaneurysm at the level of celiac artery (A) and the aorta before (B) and after (C) reconstruction with cryopreserved human aortic allograft patch 


\section{Discussion}

The reconstructions for paravisceral aortic infections face considerably more challenges than the infrarenal aortic ones. The reconstructions for suprarenal infections carried a fourfold mortality rate compared to mortality for operations performed for infrarenal infections [3]. Thoracotomy, extracorporal circulation, or debranching to the visceral arteries may be necessary for extraanatomical reconstructions. In situ reconstructions with rifampin-soaked Dacron grafts carry a high risk of reinfection [1], especially in patients with gross infection or periaortic abscess. Allografts tend to be more resistant to bacterial infection [4], but their availability in emergency situation may be limited. We have access to cryopreserved homografts from our institute's cryobank. Autologous graft may be an option; however, graft harvest may increase the operative time and can lead to additional blood loss and new surgical site infection. The endovascular repair is the least invasive of all modalities, but infection-related complication rate can be as high as $27 \%$ as shown in a multicenter study and these complications are often lethal [5].

In our patient, the in situ cryopreserved arterial allograft reconstruction proved to be a reliable solution in an infected periaortic environment that was colonized by MRSA and multiple other bacteria.

$$
\text { *** }
$$

Funding sources: There are no sources of outside support for research, including funding, equipment, and drugs.
Authors' contribution: PB carried out the literature research and the writing of the manuscript. PL contributed in the manuscript writing. $\mathrm{ZSz}$ carried out the procedure and supervised the manuscript. All authors have read and approved the final version of the manuscript.

Conflict of interest: The authors declare no conflict of interest.

\section{References}

1. Oderich GS, Panneton JM, Bower TC, Cherry KJ Jr, Rowland CM, Noel AA, Hallett JW Jr, Gloviczki P: Infected aortic aneurysms: Aggressive presentation, complicated early outcome, but durable results. J Vasc Surg 34, 900-908 (2001)

2. Biro G, Szeberin Z, Nemes A, Acsady G: Cryopreserved homograft and autologous deep vein replacement for infrarenal aorto and iliacofemoral graft infection: Early and late results. J Cardiovasc Surg (Torino) 52, 169-176 (2011)

3. Moneta GL, Taylor LM Jr, Yeager RA, Edwards JM, Nicoloff AD, McConnell DB, Porter JM: Surgical treatment of infected aortic aneurysm. Am J Surg 175, 396-399 (1998)

4. Noel AA, Gloviczki P, Cherry KJ Jr, Safi H, Goldstone J, Morasch $\mathrm{MD}$, Johansen $\mathrm{KH}$ : Abdominal aortic reconstruction in infected fields: Early results of the United States cryopreserved aortic allograft registry. J Vasc Surg 35, 847-852 (2002)

5. Sorelius K, Mani K, Bjorck M, Sedivy P, Wahlgren CM, Taylor P, Taylor $\mathrm{P}$, Clough RE, Lyons $\mathrm{O}$, Thompson $\mathrm{M}$, Brownrigg J, Ivancev K, Davis M, Jenkins MP, Jaffer U, Bown M, Rancic Z, Mayer D, Brunkwall J, Gawenda M, Kölbel T, Jean-Baptiste E, Moll F, Berger P, Liapis CD, Moulakakis KG, Langenskiöld M, Roos H, Larzon T, Pirouzram A, Wanhainen A: Endovascular treatment of mycotic aortic aneurysms: A European multicenter study. Circulation 130, 2136-2142 (2014) 